\title{
Laboratory diagnosis and epidemiology of herpes simplex 1 and 2 genital infections
}

\author{
Urška Glinšek Biškup ${ }^{1}$, Tina Uršič ${ }^{1}$, Miroslav Petrovec $^{1}$
}

\begin{abstract}
Herpes simplex virus types 1 and 2 are the main cause of genital ulcers worldwide. Although herpes simplex virus type 2 is the major cause of genital lesions, herpes simplex virus type 1 accounts for half of new cases in developed countries. Herpes simplex virus type 2 seroprevalence rises with sexual activity from adolescence through adulthood. Slovenian data in a high-risk population shows $16 \%$ seroprevalence of HSV-2. HSV-1 and HSV-2 DNA in genital swabs was detected in $19 \%$ and $20.7 \%$, respectively. In most cases, genital herpes is asymptomatic. Primary genital infection with herpes simplex virus types 1 and 2 can be manifested by a severe clinical picture, involving the vesicular skin and mucosal changes and ulcerative lesions of the vulva, vagina, and cervix in women and in the genital region in men. Direct methods of viral genome detection are recommended in the acute stage of primary and recurrent infections when manifest ulcers or lesions are evident. Serological testing is recommended as an aid in diagnosing genital herpes in patients with reinfection in atypical or already healed lesions. When herpes lesions are present, all sexual activities should be avoided to prevent transmission of infection. Antiviral drugs can reduce viral shedding and thus reduce the risk of sexual transmission of the virus.
\end{abstract}

Keywords: genital herpes, herpes simplex virus type 1 and 2, sexually transmitted infection, seroprevalence

Received: 26 March 2015 | Returned for modification: 12 April 2015 | Accepted: 29 April 2015

\section{Introduction}

Herpes simplex virus (HSV) types one and two (HSV-1 and HSV-2) are the main cause of genital herpes, which is the main cause of genital ulcers worldwide. Most genital herpes is caused by HSV-2, but more recently there has been an increase in infections caused by HSV-1 $(1,2)$. A serious complication of genital herpes is neonatal herpes, usually caused by HSV-2. It can lead to the death of a newborn, but fortunately this complication is rare. Infection is acquired most commonly via sexual activity (oral, vaginal, or anal). Most infections manifest with mild symptoms or are even asymptomatic, which increases the risk of transmission. The highest possibility of virus transmission is during outbreak periods when lesions are present. Use of antiviral agents and condoms reduces the possibility of virus transmission (3).

\section{Herpes simplex virus}

HSV-1 and HSV-2 are members of Herpesviridae family. The genomes of both types of HSV are highly identical and they share many immunogenic epitopes in the outer membrane proteins. Both types of viruses differ in envelope glycoproteins $\mathrm{G}$ ( $\mathrm{gG} 1$ and gG2). Purified glycoproteins specific for HSV-1 (gG-1) or HSV-2 (gG2) are used as antigens to detect type-specific antibodies $(4,5)$.

\section{Epidemiology}

HSV occurs worldwide, with no specific seasonal variation, and naturally can only infect humans. For infection initiation, HSV must come into direct contact with mucosal surfaces (6).

The type of HSV infection depends on the immunologic status of the infected person. Initial primary infection is manifested in persons without previously present serum antibodies against
HSV. Initial non-primary infection is manifested in persons with pre-existing antibodies to HSV-1 or HSV-2 type and a new infection with the other HSV type. Recurrent infection occurs when there are pre-existing antibodies to the same type of HSV causing current infection (2).

The virus remains in a latent stage for the life of the host. Periodic reactivations of the virus and viral shedding occur in the presence of lesions or with mild or no symptoms. Persons with the latent virus are a reservoir for virus shedding and transmission. Symptomatic recurrent infections are associated with a shorter duration of viral shedding and fewer lesions (1).

Although HSV-1 and HSV-2 infections affect different parts of the body, and have different manners of transmission, their clinical manifestations and symptoms can overlap. HSV-1 infections are usually limited to the oropharyngeal area and most commonly occur in children from 6 months to 3 years of age, rising until adolescence. HSV-2 is usually sexually transmitted, and antibodies against HSV-2 are rarely detected before adolescence (1). In recent years. the principal cause of genital herpes is HSV-1 in most women and young men, although severe genital herpes with frequent recurrences are still more commonly caused by HSV-2 $(4,7)$.

Genital herpes transmission usually occurs through genitalgenital or oral-genital contact. Transmission mostly occurs from asymptomatic carriers of the virus. On the other hand, transmission is most likely during the presence of visible lesions in the partner $(7,8)$. Only $30 \%$ of seropositive people are aware of their HSV-2 infection, and $20 \%$ of them have no symptoms. Moreover virus shedding has also been found during asymptomatic periods $(7,9,10)$. Use of condoms only partly protects from infection; condoms do not cover the entire genital area, and virus shedding is also found in parts of the genital tract without visible lesions $(7,9,10)$.

Neonatal herpes infection is rare, occurring in fewer than 1 in 
3,00o live births, but has high mortality and severe manifestations for disseminated disease (11). Infection can be acquired in utero or intrapartum. Most commonly, neonatal herpes results from exposure of a newborn to infected maternal genital secretions during delivery. During the primary infection of women, the risk for virus transmission is higher (12). Most newborn infections are due to HSV-2 (13).

Important synergy has been found between HSV-2 and human immunodeficiency virus (HIV). HSV-2 infection increases the risk of HIV infection due to mucosal disruption caused by genital ulcers, which are an entryway for HIV (4).

\section{Genital herpes prevalence}

Several factors influence the prevalence of HSV-1 and HSV-2 infections. In developed countries, including the US, HSV-1 prevalence decreased (in 1999-2004 in comparison to 1988-1994) in the general population, which correlates with a higher probability of HSV-1 genital infection. The higher probability of HSV-1 infection is due to a lower seroprevalence of HSV-1 in adolescents and changed sexual behavior that includes choosing oral sex over vaginal sex (4).

Globally, HSV-2 is still the main cause of genital herpes. With the onset of sexual activity, the prevalence of HSV-2 begins to rise, usually from adolescence through adulthood.

Women are more susceptible to HSV-2 infection than men (14). The HSV-2 prevalence rate is also higher in MSM compared to heterosexual men and in HIV-positives compared to the general population, and higher HSV-2 seroprevalence is found in urban environments compared to rural ones $(4,14)$. The risk factors for HSV-2 infection are the same as for other sexually transmitted infections (STIs): a high number of sexual partners throughout one's lifetime, young age at the onset of sexual activity, and previous history of STIs (15).

The worldwide HSV-2 seroprevalence is between 10 and $40 \%$. In Australia HSV-2 seropositivity is $13 \%$ (16), whereas in Canada and the US it is $17 \%(4,17)$ and in Central and South America between 23 and 43\% (14, 18, 19). In Europe the HSV-2 seroprevalence is between $5 \%$ and $20 \%$, and in the Middle East below $10 \%$ (14, 20-23). In Asia the HSV-2 seroprevalence is between 10 and $20 \%$, and in Africa > 50\% (24-26).

Regarding groups at higher risk for HSV-2 infection, a higher proportion of those infected is found among female sex workers and among those infected with HIV (60 to 95\%). Among pregnant women, seroprevalence of HSV-2 ranges between 7 and 42\% $(3,14)$.

\section{Genital herpes prevalence in Slovenia}

A small Slovenian survey was performed between 2006 and 2008, at the Institute of Microbiology and Immunology, Faculty of Medicine, University of Ljubljana, Slovenia in which 99 men and 128 women were included whose sera were tested due to suspicion of genital herpes sent from three different clinics for sexually transmitted diseases for determining serological status. The mean age of women was 36.7 years and for men 36.2 years. Specific HSV-1 and HSV-2 IgG antibodies were detected by enzyme-linked immunosorbent assay HerpeSelect ${ }^{\circledR}$ HSV 1 and HSV-2 IgG (Focus Diagnostics). IgG antibodies against HSV-1 were detected in $69.6 \%$ and against HSV-2 in $29.5 \%$ of patient samples examined. Infections with HSV-2 virus was more frequently detected in females, but the difference was not statistically significant (women $33.6 \%$ versus men $24.2 \%$; Fig. 1).
The HSV-2 seroprevalence increases simultaneously from puberty onwards, and in the age group $>56$ years in the women's group it reaches $50 \%$ and in the male group more than $70 \%$.

According to data obtained at the Institute of Microbiology and Immunology, Faculty of Medicine, University of Ljubljana, Slovenia, from 2009 to $2014,1,767$ serum samples (239 men and 1,528 women) were sent from various Slovenian health institutions, including clinics for sexually transmitted diseases, for the serological confirmation of genital herpes. The mean age of women was 31.4 years and for men 38 years. IgG antibodies against HSV (type-nonspecific) were detected in $85.6 \%$ (women $85.8 \%$ versus men $81.6 \%$ ) using the Enzygnost $®$ Anti-HSV/IgG Assay (Siemens Healthcare Diagnostics). Antibodies against HSV-2 were detected in $16 \%$ (women $15.6 \%$ versus men $18.6 \%$ ) of patient samples examined, using Liaison ${ }^{\circledR}$ HSV-2 IgG (DiaSorin S.p.A.). The HSV and HSV-2 seroprevalence increases with age, and in the age group > 56 years it reaches $97 \%$ for HSV (both sexes, Fig. 2A) and $48.4 \%$ for HSV-2 (women 55\% versus men 36\%; Fig 2B).

In the last 5 years, between 2009 and 2014, 174 genital swabs were sent to the Institute of Microbiology and Immunology, Faculty of Medicine Ljubljana, Slovenia, for molecular diagnostics of genital herpes. Of these, 59 swabs belonged to men and 115 swabs belonged to women. The median age of women was 37 years and for men 40 years. HSV-1 DNA was detected in $19 \%$ of all patients tested, but more frequently in women (20\%) than in men $(16.9 \%)$. HSV-2 DNA was detected in $20.7 \%$ of all patients tested, but the frequencies in both sexes were nearly the same (men 20.3\% versus women $20.9 \%$ ). Men infected with HSV-1 were younger in comparison to men in which HSV-2 DNA was detected, but the difference was not statistically significant (median 29 years vs. 41 years; $\mathrm{P}=$ 0.10). Women infected with HSV-1 were significantly younger compared to women in whom HSV-2 DNA was detected (median 22.5 years vs. 51 years; $\mathrm{P}<0.0001)$.

A Slovenian survey carried out in 2003, which included 4,000 pregnant women, showed an HSV-1 seroprevalence of $86.9 \%$ and HSV-2 seroprevalence of $9.9 \%$. In $7.1 \%$ of pregnant women, IgG against HSV-1 and HSV-2 were present, whereas $11 \%$ of pregnant women did not have HSV antibodies (27).

\section{Clinical manifestations of genital herpes}

The incubation period ranges from 2 to 10 days. Most HSV infections are subclinical. In symptomatic infections, clinical manifestations of primary infection of the genital area with HSV-1 or HSV2 are typically characterized by painful vesicular and ulcerative lesions. After acquisition of HSV infection at a mucocutaneous site, papules and macules appear, which develop into pustular

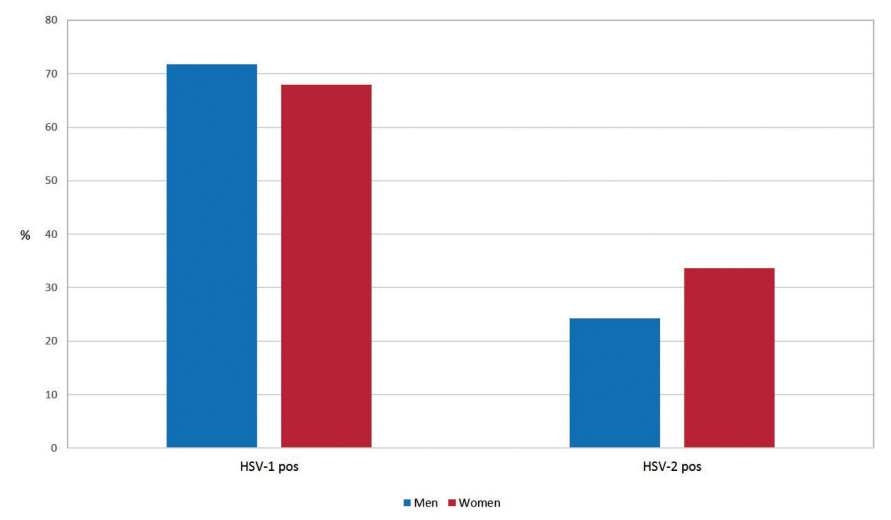

Figure 1 | Slovenian seroprevalence of HSV-1 and HSV-2 IgG in men and women. 

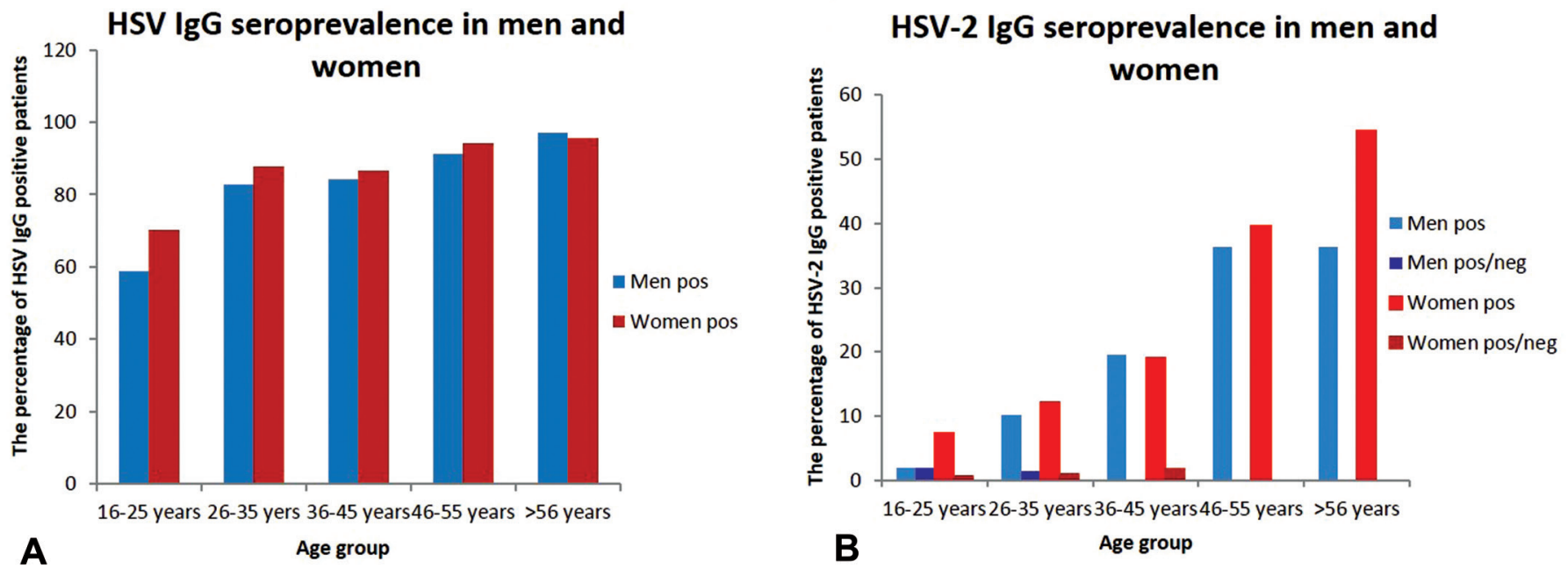

Figure 2 | Slovenian seroprevalence of HSV (Fig. 2A) and HSV-2 (Fig. 2B) in both sexes by age group.

and ulcerative lesions. After 4 to 15 days, the lesions crust and re-epithelize $(1,3)$. Primary infection can be associated with fever, dysuria, localized inguinal adenopathy, and malaise in both men and women. Paresthesias and dysesthesias that involve the lower extremities and perineum are common. In women with primary infection, lesions appear on the vulva and are usually bilateral (28), with involvement of the cervix. Lesions may involve also the perineum, buttocks, and/or vagina. In men, primary infection results in vesicular lesions on the glans of penis or the penile shaft (28). There is also a possibility of extra-genital lesions occurring in both sexes. Systemic complication in the form of aseptic meningitis can occur in both men and women. Viral excretion may persist for up to 3 weeks (1). Clinically, an acute episode of genital herpes is similar in infection regardless of the type of HSV causing infection, but recurrences are less frequent and less severe in HSV-1 infection (29).

Primary infection is associated with larger quantities of virus shedding in the genital tract and a longer period of viral shedding, on average 3 weeks (8). Systemic symptoms include headache and myalgia. Locally, fungal and bacterial superinfections can occur. The most severe clinical complication is meningitis. The presence of pre-existing antibodies to a different HSV type results in milder disease. Recurrent infections are common in the 1st year after primary infection; they are manifested with milder symptoms and shorter duration $(3,7)$.

Vertical transmission from an infected mother to fetus is usually manifested with vesicular lesions on the skin of infected babies. Infection can result in a disseminated disease in the newborn with central nervous system involvement; neonatal death of untreated newborns is up to $50 \%(11,30)$. Neonatal herpes can be localized to the skin, eye, and mouth, or is manifested in the form of encephalitis with or without skin involvement or as a disseminated infection that involves multiple organs $(31,32)$.

\section{Diagnosis}

Genital herpes can be diagnosed by clinicians if typical papular lesions progress to vesicle and ulcers are present. Although the features in patients can be highly variable, a definitive diagnosis should be confirmed with laboratory findings (33). Laboratoryconfirmed HSV diagnosis is important for appropriate treatment selection, and type identification gives important information about disease prognosis. Differentiating between HSV-1 and HSV2 is possible only with laboratory diagnostics, and laboratory confirmation is also necessary to exclude other possible causes of ulcers in the genital area (3).

With regard to different guidelines for laboratory diagnosis of genital herpes, for patients with symptoms, detection of viral DNA by nucleic acid amplification tests (NAAT) is most appropriate. Virus isolation on cell cultures can also be performed (34).

In the absence of symptoms, swab testing for preventing HSV transmission is not appropriate, because viral shedding is intermittent (8). For populations at high risk of HSV infection, serological testing is recommended. The best practice is using a combination of type-specific serologic testing and direct virus-detection methods in order to differentiate the type of infecting virus as well as primary and recurrent infections $(33,34)$. Because of their low sensitivity and specificity, cytological examination using conventional staining procedures (Tzanck smears, the Papanicolaou test, or Romanowsky stains) are not recommended for reliable diagnosis of HSV infections (33-35).

\section{Specimen collection and transportation}

The sample of choice is a swab sample of active herpetic lesions. Before sampling, necrotic tissue should be removed. Typically swabs are taken from the base of lesion (3). The sample should be taken in the first $24 \mathrm{~h}$ after the lesions occur; when crusting of lesions begins, the sensitivity of tests declines rapidly (29). In the presence of vesicles, the vesicle should be unroofed and a swab of the vesicle base should be taken. Collection of vesicular fluid or exudate from small vesicles in combination with a swab of the lesion base is also an appropriate sample $(34,36)$. When only older lesions are present, the recovery rate of HSV drops sharply; for patients with such lesions, another sampling is advised when fresh new lesions appear (36). After sampling, the swab should immediately be placed in viral transport medium (VTM) and transported to the laboratory at $4^{\circ} \mathrm{C}$. When immediate transport is not possible, samples should be placed on ice in a cooling box, without freezing, but the overall transport time should not exceed 48 hours $(29,36)$. Vesicle fluid aspiration is taken and transported in a sterile syringe; if disseminated infection is suspected, blood for PCR should be taken with anticoagulant (EDTA). Other samples that may occasionally be tested are swabs of the cervix, urethra, 
or vagina (36). The blood sample for serological methods should be taken in a tube without anticoagulant.

\section{Methods for direct detection of the virus}

For direct HSV detection, available tests include antigen detection by direct immunofluorescence, nucleic acid amplification tests (NAATs) for viral DNA detection, and viral culture (29). NAATs are currently the most sensitive and specific methods. Among them, real-time PCR is recommended as a preferred diagnostic method (37). With high sensitivity and specificity, real-time PCR offers accurate diagnosis to a clinician. It allows both typing of HSV and quantification of viral load (in fluid samples). The risk of false positive results occurring due to sample contamination before amplification should be prevented with carefully planned procedures in the molecular laboratory (29). Regarding transport and storage of samples, real-time PCR can tolerate less stringent conditions than samples for viral isolation (36). The important advantage of molecular methods is the possibility of detection of asymptomatic HSV shedding, but one should be aware that a negative PCR result does not exclude HSV infection because virus shedding is intermittent (36).

HSV antigen detection may be a suitable alternative for smaller laboratories as an alternative to viral culture or PCR when fresh lesions are present and the swab is of high quality (rich in cells). The appropriate transport conditions are less stringent than for viral culture. Demonstration of antigen with direct immunofluorescence assay (DIF) is rapid, but with lower sensitivity in comparison to PCR, and is appropriate only for patients with fresh lesions $(29,36)$.

Viral culture as a gold standard of laboratory HSV detection is possible only in highly specialized laboratories. Low-cost and well-established methodology supports the use of viral culture. This is a highly specific method, but it has low sensitivity, and appropriate sample handling with a continuous cold chain of sample transport to preserve virus viability is very important. Sensitivity is even lower for recurrences, which is why successful viral culture is mostly successful from fresh lesions in primary HSV infection $(29,35,36)$. The main advantage of viral culture is typing of viral isolates, and this is a prerequisite for phenotypic antiviral susceptibility testing (36).

\section{Antibody detection methods}

The detection of antibodies to HSV is recommended as an aid to diagnosing genital herpes and is particularly useful in identifying an asymptomatic carrier of HSV infection (29).

A defining characteristic of HSV infections is a slow antibody response. There are many tests available to detect HSV antibodies, and the majority of newer tests can now differentiate between types of HSV. Serological assays that are not type-specific are of no value in managing genital herpes (33). Differentiation of HSV types is possible on the basis of glycoprotein $\mathrm{G}$ (gG-1 and gG-2). The disadvantage of a glycoprotein-based test is an inability to detect IgM antibodies. IgM detection is possible with assays based on other groups of glycoproteins (gA- gI), but not the differentiation of HSV types $(35,36)$. Detection of HSV-2 antibodies confirm sexually transmitted infection, and detection of HSV-1 antibodies as a confirmation of genital herpes is not useful because of the high seroprevalence of HSV-1 in the general population (38).

Type-specific HSV IgG antibodies usually become detectable within 2 weeks to 3 months after the initial infection (39). For IgGnegative patients, detection of IgM antibodies increases the ability to detect early infection. Seroconversion as a confirmation of primary infection has limited application, and the occurrence of IgM antibodies is sometimes delayed, even up to 3 months after initial infection, probably due to localized infection of mucosa. IgM antibodies can also be detected during recurrent infection, and tests for IgM detection have poor sensitivity. Because of all of these limitations, serology is not optimal for confirmation of acute HSV infection $(33,36)$.

Serological testing in the general population is not recommended. Regarding different guidelines, it can be useful in the following circumstances:

- As an aid in diagnosing genital herpes infection, especially to differentiate between primary and recurrent infection;

- In patients with a history of recurrent or atypical lesions, or in patients with healing lesions with negative direct methods;

- For managing sexual partners of people with genital herpes when a risk of transmission exists;

- For identifying HSV infection in high-risk groups, although testing people in high-risk groups is not routinely recommended $(33,36)$.

Testing pregnant women for the presence of HSV antibodies is not routinely recommended in Europe. Although it is not cost-effective, rather careful examination of the vulva for the presence of lesions indicating HSV infection at the onset of delivery is advised (33). It is recommended that one define the serological status of both the pregnant woman and her partner and, in the case of HSV type mismatch or a negative status of the pregnant women, use of condoms or abstinence from direct sexual contact is advised. In newborns, detection of antibodies is not appropriate because one cannot distinguish between passive, maternal, and newborn antibodies (36).

For detecting HSV-2 antibodies, rapid point-of-care (POC) serological assays also are available. The test can be performed from capillary blood or a serum. The main advantage of assays is that they provide results rapidly, with relatively high sensitivities and specificities (38).

\section{Prevention of HSV transmission}

Screening of the general population is not recommended. If serology is performed in patients without any history of genital herpes, appropriate counseling should be provided (2).

During the presence of lesions, patients are advised to abstain from all sexual contact. Condom use is advisable and could prevent the majority of infection if properly used (40). However, transmission of virus is also possible from parts of the genital area without visible lesions, and areas that cannot be covered by a condom, and so protection is still only partial $(7,9,10,40)$.

Antiviral drugs can reduce viral shedding and thus reduces the risk of virus transmission $(3,33)$. There are no specific recommendations regarding management of partners of HSV-positive patients, but testing and counseling should be offered to partners $(2,33)$.

Pregnant women with recurrent genital herpes have a low risk of transmission of infection to the fetus or newborn. There is currently no reliable method to identify women that are asymptomatically shedding HSV at the time of delivery $(12,33)$.

If there are no genital lesions visible at the time of delivery, even for seropositive pregnant women, there is no indication for 
a cesarean section (41). The exception is pregnant women that acquire HSV infection in the third trimester, especially if symptoms of genital herpes develop in the period 6 weeks before delivery. For these cases, most guidelines recommend delivery with a cesarean section because of the very high risk of viral shedding $(12,33,41)$.

There is no effective vaccine available, but intensive studies are in progress $(42,43)$

\section{Acknowledgement}

This work was supported by the Slovenian Research Agency (Research Program P3-0083).

\section{References}

1. Knipe DM, Howley PM. Fields virology. 6th ed. Philadelphia (PA): Wolters Kluwer Health/Lippincott Williams \& Wilkins; c2013. Chapter 60, Herpes simplex viruses; p. 1823-97.

2. Garland SM, Steben M. Genital herpes. Best Pract Res Clin Obstet Gynaecol. 2014;28:1098-110.

3. Gupta R, Warren T, Wald A. Genital herpes. Lancet. 2007;370:2127-37.

4. Xu F, Sternberg MR, Kottiri BJ, McQuillan GM, Lee FK, Nahmias AJ, et al. Trends in herpes simplex virus type 1 and type 2 seroprevalence in the United States. JAMA. 2006;296:964-73.

5. Strick L, Wald A. Type-specific testing for herpes simplex virus. Expert Rev Mol Diagn. 2004;4:443-53.

6. Whitley RJ, Roizman B. Herpes simplex virus infections. Lancet. 2001;357:1513-8.

7. Patel R. Genital herpes. Medicine. 2014;42:354-8.

8. Tronstein E, Johnston C, Huang ML, Selke S, Magaret A, Warren T, et al. Genital shedding of herpes simplex virus among symptomatic and asymptomatic persons with HSV-2 infection. JAMA. 2011;305:1441-9.

9. Johnston C, Zhu J, Jing L, Laing KJ, McClurkan CM, Klock A, et al. Virologic and immunologic evidence of multifocal genital herpes simplex virus 2 infection. J Virol. 2014;88:4921-31.

10. Schiffer JT, Corey L. Rapid host immune response and viral dynamics in herpes simplex virus-2 infection. Nat Med. 2013;19:280-90.

11. Stephenson-Famy A, Gardella C. Herpes simplex virus infection during pregnancy. Obstet Gynecol Clin North Am. 2014;41:601-14

12. Brown ZA, Wald A, Morrow RA, Selke S, Zeh J, Corey L. Effect of serologic status and cesarean delivery on transmission rates of herpes simplex virus from mother to infant. JAMA. 2003;289:203-9.

13. Pirš $M$, Paro Panjan D. Okužbe $z$ virusom herpes simpleks pri nosečnicah in novorojenčkih. [Herpes simplex infection during pregnancy and the neonatal period]. Medicinski razgledi. 2006;45(Suppl 3):97-108. Slovene.

14. Smith JS, Robinson NJ. Age-specific prevalence of infection with herpes simplex virus types 2 and 1: a global review. J Infect Dis. 2002;186(Suppl 1):S3-28.

15. Mertz GJ, Benedetti J, Ashley R, Selke SA, Corey L. Risk factors for the sexual transmission of genital herpes. Ann Intern Med. 1992;116:197-202.

16. Sasadeusz II, Silvers JE, Kent HE, Devenish W, Hocking J, Garland SM. Prevalence of HSV-2 antibody in a Melbourne antenatal population attending a tertiary obstetric hospital. Aust N Z J Obstet Gynaecol. 2008;48:266-72.

17. Patrick DM, Dawar M, Cook DA, Krajden M, Ng HC, Rekart ML. Antenatal seroprevalence of herpes simplex virus type 2 (HSV-2) in Canadian women: HSV-2 prevalence increases throughout the reproductive years. Sex Transm Dis. 2001; 28:424-8

18. Carvalho M, de Carvalho S, Pannuti CS, Sumita LM, de Souza VA. Prevalence of herpes simplex type 2 antibodies and a clinical history of herpes in three different populations in Campinas City, Brazil. Int I Infect Dis. 1998;3:94-8.

19. Hildesheim A, Mann V, Brinton LA, Szklo M, Reeves WC, Rawls WE. Herpes simplex virus type 2: a possible interaction with human papillomavirus types $16 / 18$ in the development of invasive cervical cancer. Int J Cancer. 1991;49:335-40.

20. Rabenau HF, Buxbaum S, Preiser W, Weber B, Doerr HW. Seroprevalence of herpes simplex virus types 1 and type 2 in the Frankfurt am Main area, Germany. Med Microbiol Immunol. 2002;190:153-60.

21. de Ory F, Pachon I, Echevarria JM, Ramirez R. Seroepidemiological study of herpes simplex virus in the female population in the autonomous region of Madrid, Spain. Eur J Clin Microbiol Infect Dis. 1999;18:678-80.

22. Vyse AJ, Gay NJ, Slomka MJ, Gopal R, Gibbs T, Morgan-Capner P, et al. The burden of infection with HSV-1 and HSV-2 in England and Wales: implications for the changing epidemiology of genital herpes. Sex Transm Infect. 2000;76:183-7.

23. Isacsohn M, Smetana Z, Rones ZZ, Raveh D, Diamant Y, Samueloff A, et al. A sero-epidemiological study of herpes virus type 1 and 2 infection in Israel. J Clin Virol. 2002;24:85-92.
24. Eberhart-Phillips JE, Dickson NP, Paul C, Herbison GP, Taylor J, Cunningham AL. Rising incidence and prevalence of herpes simplex type 2 infection in a cohort of 26 year old New Zealanders. Sex Transm Infect. 2001;77:353-7.

25. Auvert B, Ballard R, Campbell C, Carael M, Carton M, Fehler G, et al. HIV infection among youth in a South African mining town is associated with herpes simplex virus-2 seropositivity and sexual behaviour. AIDS. 2001;15:885-98.

26. Weiss HA, Buve A, Robinson NJ, Van Dyck E, Kahindo M, Anagonou S, et al. The epidemiology of HSV-2 infection and its association with HIV infection in four urban African populations. AIDS. 2001;15(Suppl 4):S97-108.

27. Lorber N. Primerjava prekuženosti nosečnic z virusoma herpes simplex tipa in $2 \mathrm{v}$ Sloveniji $\mathrm{v}$ desetletnem razmiku [The comparison of herpes simplex type 1 and 2 prevalence in pregnant women in Slovenia during a ten-year period; bachelor's thesis]. Ljubljana: University of Ljubljana; 2006. 64 p. Slovene.

28. Knipe DM, Howley PM. Fields virology. 5 th ed. Philadelphia (PA): Wolters Kluwe Health/Lippincott Williams \& Wilkins; c2007. Herpes simplex viruses; p. 2501602.

29. Singh A, Preiksaitis J, Ferenczy A, Romanowski B. The laboratory diagnosis of herpes simplex virus infections. Can J Infect Dis Med Microbiol. 2005;16:92-8.

30. Kimberlin DW. Neonatal herpes simplex infection. Clin Microbiol Rev. 2004;17:1-13.

31. Kimberlin DW, Lin CY, Jacobs RF, Powell DA, Corey L, Gruber WC, et al. Safety and efficacy of high-dose intravenous acyclovir in the management of neonatal herpes simplex virus infections. Pediatrics. 2001;108:230-8

32. Whitley RJ, Soong SJ, Hirsch MS, Karchmer AW, Dolin R, Galasso G, et al. Herpes simplex encephalitis: vidarabine therapy and diagnostic problems. N Engl J Med. 1981;304:313-8.

33. Patel R, Alderson S, Geretti A, Nilsen A, Foley E, Lautenschlager S, et al. $2010 \mathrm{Eu}$ ropean guideline for the management of genital herpes [Internet]. c2010 - [cited 2015 Apr 8]. Available from: http://www.iusti.org/regions/europe/pdf/2010/ Euro Guideline 2010_herpes.pdf.

34. Domeika M, Bashmakova M, Savicheva A, Kolomiec N, Sokolovskiy E, Hallen A, et al. Guidelines for the laboratory diagnosis of genital herpes in eastern European countries. Euro Surveill. 2010;15

35. Anderson NW, Buchan BW, Ledeboer NA. Light microscopy, culture, molecular, and serologic methods for detection of herpes simplex virus. J Clin Microbiol. 2014:52:2-8.

36. Belec A. Herpes simplex virus (HSV) infections. Laboratory diagnosis of sexually transmitted infections, including human immunodeficiency virus. [Internet]. World Health Organization; c2013 - [cited 2015 Apr 8]. Available from: http:// apps.who.int/iris/bitstream/10665/85343/1/9789241505840_eng.pdf?ua=1.

37. van Doornum GJ, Guldemeester J, Osterhaus AD, Niesters HG. Diagnosing herpesvirus infections by real-time amplification and rapid culture. J Clin Microbiol. 2003;41:576-80.

38. Wald A, Ashley-Morrow R. Serological testing for herpes simplex virus (HSV)-1 and HSV-2 infection. Clin Infect Dis. 2002;35(Suppl 2):S173-82.

39. Ashley RL, Wald A. Genital herpes: review of the epidemic and potential use of type-specific serology. Clin Microbiol Rev. 1999;12:1-8.

40. Stanaway JD, Wald A, Martin ET, Gottlieb SL, Magaret AS. Case-crossover analysis of condom use and herpes simplex virus type 2 acquisition. Sex Transm Dis. 2012;39:388-93.

41. Straface G, Selmin A, Zanardo V, De Santis M, Ercoli A, Scambia G. Herpes simplex virus infection in pregnancy. Infect Dis Obstet Gynecol. 2012;2012:1-6.

42. Belshe RB, Leone PA, Bernstein DI, Wald A, Levin MJ, Stapleton JT, et al. Efficacy results of a trial of a herpes simplex vaccine. N Engl J Med. 2012;366:34-43.

43. Zhu XP, Muhammad ZS, Wang JG, Lin W, Guo SK, Zhang W. HSV-2 Vaccine: current status and insight into factors for developing an efficient vaccine. VirusesBasel. 2014;6:371-90. 